\title{
Stronger regional biosecurity is essential to prevent hundreds of harmful biological invasions
}

\author{
Katelyn T. Faulkner ${ }^{1,2}$ (D) | Mark P. Robertson ${ }^{2}$ (D) | John R. U. Wilson ${ }^{1,3}$ (D)
}

${ }^{1}$ South African National Biodiversity Institute, Kirstenbosch Research Centre, Claremont, South Africa

${ }^{2}$ Centre for Invasion Biology, Department of Zoology and Entomology, University of Pretoria, Hatfield, South Africa

${ }^{3}$ Centre for Invasion Biology, Department of Botany and Zoology, Stellenbosch University, Matieland, South Africa

\section{Correspondence}

Katelyn T. Faulkner, South African National Biodiversity Institute, Kirstenbosch Research Centre, Claremont 7735, South Africa.

Email: katelynfaulkner@gmail.com

Funding information

South African National Department of

Environment, Forestry and Fisheries

\begin{abstract}
Biological invasions often transcend political boundaries, but the capacity of countries to prevent invasions varies. How this variation in biosecurity affects the invasion risks posed to the countries involved is unclear. We aimed to improve the understanding of how the biosecurity of a country influences that of its neighbours. We developed six scenarios that describe biological invasions in regions with contiguous countries. Using data from alien species databases, socio-economic and biodiversity data and species distribution models, we determined where 86 of 100 of the world's worst invasive species are likely to invade and have a negative impact in the future. Information on the capacity of countries to prevent invasions was used to determine whether such invasions could be avoided. For the selected species, we predicted 2,523 discrete invasions, most of which would have significant negative impacts and are unlikely to be prevented. Of these invasions, approximately a third were predicted to spread from the country in which the species first establishes to neighbouring countries where they would cause significant negative impacts. Most of these invasions are unlikely to be prevented as the country of first establishment has a low capacity to prevent invasions or has little incentive to do so as there will be no impact in that country. Regional biosecurity is therefore essential to prevent future harmful biological invasions. In consequence, we propose that the need for increased regional co-operation to combat biological invasions be incorporated in global biodiversity targets.
\end{abstract}

\section{KEYWORDS}

alien species, impacts, international co-operation, pathways of introduction, proactive response capacity, species distribution models

\section{1 | INTRODUCTION}

Biological invasions are one of the greatest threats to biodiversity (Bellard, Cassey, \& Blackburn, 2016; McGeoch et al., 2010; Sala et al., 2000) and a major threat to food production, human health and livelihoods (Pimentel et al., 2001; Pimentel, Zuniga, \& Morrison, 2005). Global trade and transport play an important role in the movement of alien species around the globe (Turbelin, Malamud, \& Francis, 2017; van Kleunen et al., 2015), and as trade and transport have increased in intensity over time (Harrari, 2015), so too has the number of alien species introductions (Hulme, 2009; Seebens et al., 2017).

A principle aim of biosecurity is to either prevent the introduction of harmful species (often the most efficient and cost-effective way to manage biological invasions; Leung et al., 2002; Puth \& Post, 2005; Simberloff et al., 2013), or to detect and manage incursions soon after introduction (Simberloff et al., 2013). To achieve this, biosecurity measures at various spatial scales have been developed to 
prevent harmful alien species from being transported, to detect and respond to these species when they arrive in new regions and, where required, to prevent them from escaping or being released from confinement (Sikes et al., 2018; Wilson, Panetta, \& Lindgren, 2017). At a global level, a number of international agreements have been instituted (e.g. the Agreement on the Application of Sanitary and Phytosanitary Measures and the International Convention for the Control and Management of Ships' Ballast Water and Sediments), and international standards have been set to prevent the transportation of harmful alien species (Brenton-Rule, Barbieri, \& Lester, 2016; McGeoch et al., 2010; Turbelin et al., 2017). At a national level, countries have developed legislation that aims to prevent invasions, and have implemented a range of biosecurity interventions (Early et al., 2016; McGeoch et al., 2010; Sikes et al., 2018). However, although both international and national-level responses have increased over time, countries differ with regard to their capacity to prevent invasions, their biosecurity protocols and their implementation of international standards (Bacon, Bacher, \& Aebi, 2012; Early et al., 2016; Eschen et al., 2015; McGeoch et al., 2010; Ricciardi et al., 2017; Turbelin et al., 2017).

Intercountry variation in the implementation of international standards means that alien species can be easily transported to new regions (Ricciardi et al., 2017; Sikes et al., 2018), while at a national level, a low capacity to prevent invasions and poorly developed biosecurity protocols puts a country at risk of new introductions and invasions (Early et al., 2016). However, the risks posed by an alien species will vary between countries (Benedict, Levine, Hawley, \& Lounibos, 2007; Thuiller et al., 2005) and, therefore, so too will the incentive to prevent invasions. Biological invasions often transcend political boundaries (Stoett, 2007), and once a species is introduced and establishes in a country that shares land borders with other countries, preventing the species from spreading into neighbouring countries is extremely difficult (Faulkner, Hurley, Robertson, Rouget, \& Wilson, 2017). Intercountry variation in biosecurity (termed 'heterogenous biosecurity' in this paper) and in incentives to prevent invasions can, therefore, lead to the introduction and establishment of alien populations that can pose a risk to neighbouring countries, including those with good biosecurity (Bacon et al., 2012). In Europe, for example, inspections are only implemented at the first point of entry, but European countries implement differing inspection protocols, and so countries with weaker border controls act as a gateway for harmful species (Bacon et al., 2012). Although the biosecurity of European countries has been shown to influence that of their neighbours (Bacon et al., 2012), there have been few studies into how heterogenous biosecurity influences the likelihood that species will invade and have an impact in regions with contiguous countries (where multiple countries share land borders).

We aimed to improve the understanding of how the biosecurity of a country influences that of its neighbours. Here we present scenarios that describe invasions in regions with contiguous countries. These scenarios consider whether the invasive species spreads from the country where it first establishes into neighbouring countries, as well as whether the invasion has an impact in the country of first establishment and in those that are subsequently invaded. In order to assess how prevalent these scenarios might be in the future, we used data from alien species databases, socio-economic and biodiversity data, and species distribution models to predict future biological invasions, and classified each invasion according to the scenarios. Information on the capacity of countries to prevent invasions (termed 'proactive response capacity'; Early et al., 2016) was used to determine which invasions are unlikely to be prevented. This study indicates that biological invasions that span multiple countries are likely to be prevalent in the future, and highlights the biosecurity implications for the countries involved.

\section{2 | MATERIALS AND METHODS}

\section{1 | Invasion scenarios}

Six scenarios were developed to describe invasions in regions where multiple countries share land borders. The scenarios depict invasions whereby an alien species is introduced and establishes in a country (termed 'country of first establishment' FE) within a region where the species did not previously occur. The scenarios consider whether the species subsequently invades neighbouring countries (termed 'country of subsequent invasion' [SI]), and whether the invasion has an impact in FE or SI. In these scenarios the initial introduction of the species to FE could occur through any human-mediated introduction pathway (CBD, 2014), however, the scenarios do not differentiate between the pathways. The spread of a species from FE into SI occurs through natural dispersal (termed the 'unaided pathway' in CBD, 2014), or through human-mediated dispersal between contiguous countries that is impractical to prevent. In this paper, territories were considered as separate 'countries' from their sovereign states. It was also assumed that in regions with contiguous countries the biosecurity of these countries would be highly interdependent, while that of isolated countries (e.g. Australia) would be less dependent (Eschen et al., 2015). Details on the invasion scenarios are provided in Figure 1.

\section{2 | Preventing future biological invasions}

Biological invasions are a multistage process, and for a species to become invasive, it must be introduced to a region where it is not native, establish a population and then spread (Blackburn et al., 2011). We considered each stage of the invasion process and determined where future biological invasions could occur in regions with contiguous countries and whether these invasions could cause impacts. We then assessed whether such invasions are likely to be prevented. The procedure followed is set out in Figure 2: (1) collate data for study species and determine where each species is likely to (2) be introduced ('introduction threat'), (3) become invasive ('invasion threat') and (4) have an impact; (5) classify the invasions according to the relevant invasion scenarios; and (6) for each invasion 


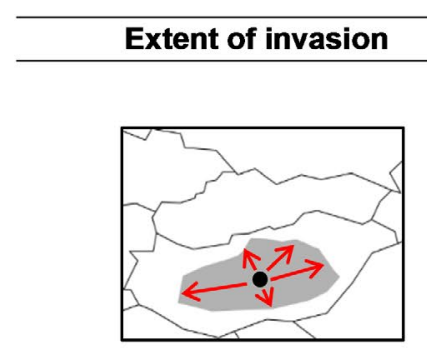

Species is introduced and establishes in a country, but there is no subsequent spread into neighbouring countries.

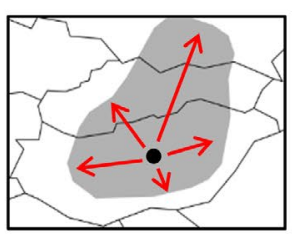

Species is introduced and establishes in a country, and there is subsequent spread into neighbouring countries.

\section{Country borders}

- First introduction Extent of invasion $\rightarrow$ Direction of spread
1. The invasion causes no impacts in the country of first establishment (FE), and there is no spread into other countries (i.e. no subsequent invasions [SI]).

2. The invasion causes impacts in the country of first establishment and there is no spread into other countries.

3. The invasion causes no impacts in either the country of first establishment or in countries where there are subsequent invasions.

\section{The invasion causes} impacts in both the country of first establishment and in countries where there are subsequent invasions.

5. The invasion causes impacts in the country of first establishment, but not in countries where there are subsequent invasions.

6. The invasion causes no impacts in the country of first establishment, but there are impacts in countries where there are subsequent invasions.

\section{Global Change Biology-WILEY for regulation or management.}

Notation Implications

FE -X-> SI The invasion is not a high national priority

$\mathrm{FE}^{*}-\mathrm{X}->\mathrm{SI} \quad$ The invasion is a national priority for management (i.e. there should be investment in prevention, incursion response, containment or maintenance management, depending on what is most cost effective).

The invasion is not a national biosecurity priority in the country in which it is likely to first establish and is not a regional biosecurity priority.

$\begin{array}{ll}\text { FE ---> SI } & \text { The invasion is not a national biosecurity } \\ \text { priority in the country in which it is likely to } \\ \text { first establish and is not a regional } \\ \text { biosecurity priority. }\end{array}$

$\mathrm{FE}^{*}--->\mathrm{SI}^{*}$

The invasion is a regional biosecurity priority. It is a national priority in the country in which it is likely to first establish and in at least some of the countries into which it is likely to spread.

$\mathrm{FE}^{*} \rightarrow \mathrm{SI}$

The invasion is a national biosecurity priority in the country in which it is likely to first establish, but the invasion is not a regional biosecurity priority.

FE --> SI*

The invasion is a regional biosecurity priority, and affected countries will depend on the biosecurity of countries where the invasion is not a national priority. This scenario has the largest potential for conflicts of interest, as the country of first establishment might benefit from the alien species, but impacts in other countries will only occur after a number of years.

FE is the country of first establishment; SI is the country of subsequent invasion; ---> is spread; -X-> is no spread; *there are impacts; no asterisk there are no impacts

FIGURE 1 Scenarios for invasions that occur in regions with contiguous countries and the biosecurity implications

use information on biosecurity to determine whether the invasion is likely to be prevented. More detailed information on these methods can be found in the Supporting Information.

\subsection{1 | Species data}

For this study, our aim was to select a sample of well-studied invasive species from a variety of environments and taxonomic groups that have had serious impacts in places where they have been introduced. Therefore, for the analysis we selected the species on the Global Invasive Species Database's (GISD) list of 100 of the world's worst invasive species (Lowe, Browne, Boudjelas, \& De Poorter, 2000; Luque et al., 2014). Information was required for the analysis on the species' taxonomy, habitat, pathways of introduction, impacts and global range; and species occurrence records were required to model the distribution of the species (section 1 of Figure 2). For each species, information on taxonomy, habitat and impacts was obtained from the GISD, while information on the species' pathways of introduction was obtained from the GISD, CABI's Invasive Species Compendium and published literature (see Supporting Information for further details). The species' habitat was classified as either terrestrial, marine or freshwater; the pathways were classified using the scheme adopted by the Convention on 


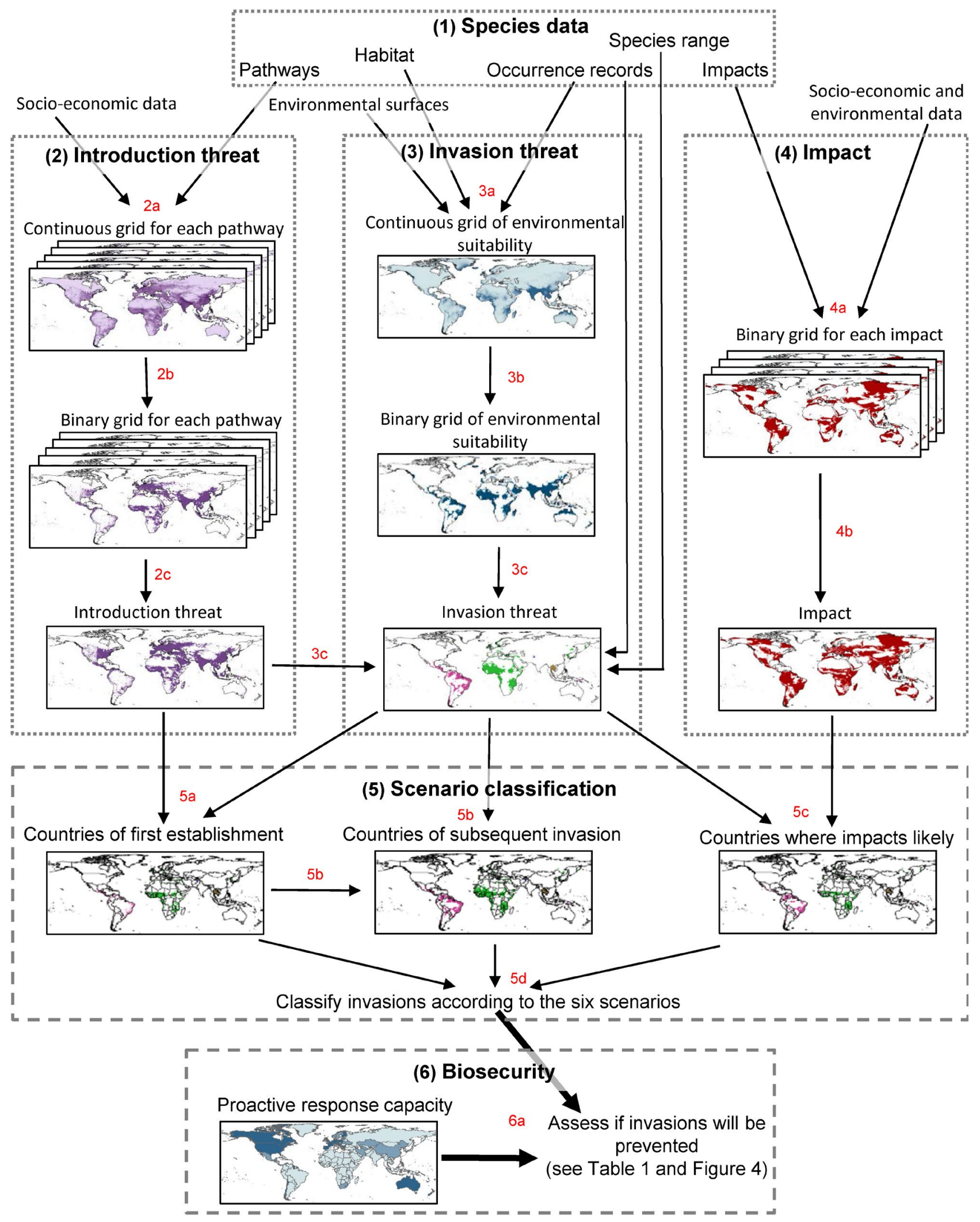

FIGURE 2 The procedure followed to determine where future biological invasions could occur and have impacts in regions with contiguous countries, and to assess whether these invasions will be prevented. The numbered sections in bold in the figure correspond to the sections of the methods where details are provided on the processes followed and their outputs. Processes are indicated in the figure using a number and lower case letter (e.g. 2a). The grey stippled boxes indicate procedures that were followed for each species, while the boxes with the grey dashed line indicate procedures that were followed for each invasion per species. The thick arrows indicate where multiple scenarios could be possible for each invasion 
Biological Diversity [CBD (CBD, 2014)] into six pathway categories and 44 subcategories (Table S3); and impacts were classified according to the GISD into three outcome categories and 40 subcategories (see Table S5). Species occurrence data were obtained from nine online databases including the Global Biodiversity Information Facility, Ocean Biogeographic Information System and eBird (see Supporting Information for further details), and information on the countries in which each species occurs as either a native or alien species was obtained from the GISD and the Global Register of Introduced and Invasive Species (Pagad, Genovesi, Carnevali, Schigel, \& McGeoch, 2018). Viruses ( $n=1)$, Protista $(n=1)$ and fungi $(n=5)$ were excluded from the analysis (for details see Table S1), as were seven species for which fewer than 30 species occurrence records were available for species distribution modelling (see below for further information). Therefore, 86 species were included in the analysis.

\subsection{2 | Introduction threat}

The likelihood of a species being introduced to a new region is often positively related to the prominence of the species' pathways of introduction in that region (Haack, 2001; Levine \& D'Antonio, 2003). For example, invertebrates or pathogens that are accidentally introduced along with their host plants when the host is intentionally imported ('contaminant on plants' or 'parasites on plants' pathways of the CBD, 2014), are more likely to be introduced to regions where large quantities of the host are imported than to regions where the host is imported in small quantities (Sikes et al., 2018). As another example, marine alien species that are transported by ships ('hull fouling' or 'ballast water' pathways of the CBD, 2014) are more likely to be introduced to regions with a high shipping intensity than to those where shipping intensity is low (Drake \& Lodge, 2004; Kaluza, Kölzsch, Gastner, \& Blasius, 2010; Seebens, Gastner, $\&$ Blasius, 2013). In order to determine where each species is likely to be introduced (section 2 of Figure 2) global socio-economic data that are related to each of the 44 pathways of introduction were collected from various online sources (for information on the types of data used for each pathway and their sources see the Supporting Information). For example, country-level data on live plant imports were obtained from the UN-Comtrade database (https://comtrade. un.org/) as these data are related to the 'contaminant on plants' and 'parasites on plants' pathways, while global cargo ship track data were obtained from Halpern et al. (2015) for the 'ballast water' and 'hull fouling' pathways. The socio-economic data were used to create a continuous $10 \mathrm{~min}$ global grid for each pathway (process $2 \mathrm{a}$ in Figure 2), where grid cells with high values represent sites where the pathway is prominent and where a species is likely to be introduced through that pathway. The continuous grid for each pathway was then converted into a binary grid ( 1 or 0 ) using the 75 th percentile as a threshold (process $2 b$ in Figure 2), where grid cells with a value of one represent sites where an alien species could be introduced through the pathway. Some alien species can be introduced through multiple pathways (Essl et al., 2015; Foxcroft, Spear, van Wilgen, \& McGeoch, 2019; Pergl et al., 2017). Using the information collected on the species' pathways of introduction (section 1 of Figure 2), we identified all of the pathways that had previously facilitated the introduction of each species to parts of the world where it is not native. For each species, the binary grids for all of the species' pathways of introduction were combined by taking the maximum value for each cell (process $2 c$ in Figure 2 ). This resulted in a binary grid ( 1 or 0 ) for each species indicating sites where the species is likely to be introduced, or in other words where the species poses an introduction threat.

\subsection{3 | Invasion threat}

Species distribution models (SDMs) were used to identify parts of the globe that are environmentally suitable for each species to survive and persist (section 3 of Figure 2). For each species, information on habitat, species occurrence records (section 1 of Figure 2) and ecologically relevant predictor variables were required for modelling.

The quality of the species occurrence records that were collected for each species (section 1 of Figure 2) was assessed using the 'Biogeo' package in R (Robertson, Visser, \& Hui, 2016), and records with errors were either corrected or removed. Records that were removed included those that were missing co-ordinate data, those that were too imprecise for the analysis and duplicate records (for further details see Table S6). As SDMs do not predict consistently well with a sample size of fewer than 30 occurrence records (Wisz et al., 2008), SDMs were built for all species for which more than 30 clean occurrence records were available (86 species). An average of 2,500 clean occurrence records per species were available for modelling (range 46-47,594, for details see Table S6).

Climatic variables from the Worldclim 10 min data set (Hijmans, Cameron, Parra, Jones, \& Jarvis, 2005) were used to model the distributions of the terrestrial and freshwater species, but for freshwater species a topographic variable-topographic wetness index from the Envirem data set (Title \& Bemmels, 2018) was also used. Marine environmental variables from the Bio-ORACLE data set (Tyberghein et al., 2012) aggregated to a 10 min resolution were used to model the distributions of the marine species. For each habitat, we selected predictor variables that have an important influence on organisms and their distributions, and that have been successfully used to model the distributions of species. The selected variables were checked for colinearity using the Pearson correlation coefficient, and in instances of colinearity one of the colinear variables was excluded. Seven climatic variables were used to model the distributions of the terrestrial species, eight climatic and topographic variables were used for the freshwater species and eight marine environmental variables were used for the marine species (for further details see Table S7).

The cleaned occurrence records and environmental predictors were used to build an ensemble species distribution model for each 
species (process 3a of Figure 2) using the 'Biomod2' package in R (Thuiller, Lafourcade, Engler, \& Araújo, 2009). The SDMs were built using six algorithms: (a) generalized linear models, (b) generalized boosting trees, (c) multivariate adaptive regression splines, (d) random forest, (e) flexible discriminate analysis and (f) maximum entropy. Five sets of pseudo-absence records were generated for each species by selecting 1,000 or 10,000 random points (depending on the number of clean occurrence records available) from the environments in which the species is found. The models were evaluated using a fourfold repeated split procedure, whereby models were calibrated on $70 \%$ of the data and tested on $30 \%$ of the data. Two test statistics, the area under the receiver operating curve (AUC; Fielding \& Bell, 1997) and the true skill statistic (TSS; Allouche, Tsoar, \& Kadmon, 2006), were used to evaluate the models. The final ensemble model for each species was generated using all the data and by calculating the weighted mean of the probabilities for each algorithm. Only models with TSS greater than 0.6 were used in the ensemble model and were weighted in proportion to the TSS evaluation. The projected ensemble models performed well for all species, with TSS values ranging between 0.69 and 0.98 , and AUC values ranging between 0.93 and 0.99 (Figure S2). The continuous SDM outputs were converted into binary grids (1 or 0 ), using the lowest predicted value at which an occurrence record was found as the threshold (process $3 \mathrm{~b}$ of Figure 2). These binary grids indicated sites that are suitable for the species to survive and persist.

As some of the species have already been introduced to parts of the world that were predicted as environmentally suitable, and as the focus of the work was on future rather than current biological invasions, we excluded predicted cells in countries in which the species already occur (process $3 c$ of Figure 2). The species occurrence data and information on the species' ranges (section 1 of Figure 2) were used to identify any country in which the species occurs, and these grid cells were excluded. For each species, the predicted cells were then classified into separate invasions based on whether the cells formed a contiguous group and whether they fell within the same political boundaries, with separate contiguous groups of cells found within the same country classified as the same invasion (process $3 c$ of Figure 2). Therefore, multiple invasions are possible for each species. Invasions that were predicted to occur on land masses where only one country is present were excluded (e.g. Australia), as were invasions for which there was no introduction threat (process $3 \mathrm{c}$ of Figure 2). This resulted in a grid for each species which indicates sites where the environment is suitable for the species to establish in the future, or in other words where the species poses an invasion threat, with all the cells related to a specific invasion uniquely classified.

\subsection{4 | Impact}

Alien species can have a wide range of environmental and socioeconomic impacts, however, the magnitude of these impacts will partly depend on the properties of the invaded site. Sensitive sites are those where the consequences of the invasion are severe or where the invasion is particularly undesirable (McGeoch et al., 2016). For example, alien species that cause a reduction in native biodiversity are likely to have the greatest impact in regions that have been identified as global conservation priorities. As another example, invasions by species that have impacts on tourism may be particularly undesirable in regions where tourism is economically important. In order to determine where each species is likely to have an especially undesirable negative impact (section 4 of Figure 2), global environmental and socio-economic data that are related to the 40 types of impact were obtained from various online databases (for information on the types of data used for each type of impact and their sources see the Supporting Information). For example, digital data for the Global 200 Ecoregions from the World Wildlife Fund (World Wildlife Fund, 2012) were used to identify sites that are a priority for conservation and that are, therefore, particularly sensitive to invasions by species that cause a reduction in native biodiversity. As another example, countrylevel data on the contribution of tourism to Gross Domestic Product obtained from the World Travel and Tourism Council (2016) were used to identify sites where tourism is economically important and that are sensitive to invasions by species that have impacts on tourism. The socio-economic data were used to create a global binary grid ( 1 or 0 ) for each type of impact (process 4 a of Figure 2), where grid cells with a value of one represent sites that are particularly sensitive to invasions. Using the information collected on the species impacts (see section 1 of Figure 2), we identified all of the impacts each species has had in their introduced range. An alien species can have multiple impacts, and so for each species, we combined the binary grids for all of the impacts that the species has had by taking the maximum value for each cell (process $4 b$ in Figure 2). This resulted in a global binary grid ( 1 or 0 ) for each species, which indicates sensitive sites where the species could have an impact if it is introduced.

\subsection{5 | Scenario classification}

The introduction threat, invasion threat and impact results were combined and a map of the country boundaries was then used to identify the countries where, for each invasion, the species is likely to first establish, subsequently invade and have an impact (section 5 of Figure 2).

We assumed that the country of first establishment for an invasion would be any country with sites where the species is likely to be introduced and subsequently establish. Therefore, for each invasion, sites where the species could first establish were identified by combining the introduction threat and invasion threat grids by calculating the product for each cell (process 5 a of Figure 2). A map of country boundaries was obtained from Natural Earth (version 2.2.0 at a scale of 1:50) and was superimposed onto the resultant grid (process 5 a of Figure 2 ) to identify the country, for each invasion, where the species could first establish. 
For each invasion, countries where the species could subsequently invade were identified by superimposing a map of country boundaries onto the invasion threat grid and eliminating the country of first establishment (process $5 b$ in Figure 2).

We assumed that countries where the species could have an impact would be any country with sensitive sites where the species is likely to establish. Therefore, for each invasion, sites where the species could have an impact were identified by combining the invasion threat and impact grids by calculating the product for each cell (process $5 c$ of Figure 2). For each invasion, countries where the species could have an impact were identified by superimposing a map of country boundaries onto the resultant grid (process $5 \mathrm{c}$ in Figure 2).

Finally, for each invasion, the countries where the species is likely to first establish, subsequently invade and have an impact were compared and each country was classified as (a) a country of first establishment where there is no impact, (b) a country of first establishment where there is an impact, (c) a country of subsequent invasion where there is no impact or (d) a country of subsequent invasion where there is an impact (process $5 d$ in Figure 2). The invasions were then classified according to the invasion scenario(s) to which they conform (process $5 d$ in Figure 2). For some invasions there was more than one country where first establishment could occur, and as a consequence, multiple scenarios are possible. In these instances, the invasions were classified according to all the invasion scenarios that were applicable.

\subsection{6 | Biosecurity}

Country-level data on proactive response capacity have been published by Early et al. (2016). These data indicate the likelihood that invasions will be prevented or contained early in the invasion process. Countries that have a high proactive response capacity have comprehensive border control policies and programmes for research, monitoring and public engagement on biological invasions (Early et al., 2016). National reports on the implementation of the Convention on Biological Diversity were used to estimate proactive response capacity, with estimates ranging between zero and three at intervals of 0.5 (Early et al., 2016). These data were used to determine, for each invasion, the proactive response capacity of the country of first establishment and assess if the invasion is likely to be prevented (process 6 a in Figure 2). We classified proactive response capacity into three categories, where a proactive response capacity of $0,0.5$ or 1 was low, 1.5 or 2 was intermediate and 2.5 or 3 was high. For invasions where first establishment could occur in more than one country multiple scenarios are possible, and for each possible scenario the proactive response capacity available to prevent the invasion could vary depending on the country where the species first establishes. In these instances proactive response capacity was assessed for each possible scenario by calculating the minimum proactive response capacity of the countries of first establishment. Furthermore, in instances where first establishment could occur in more than one country, countries of first establishment with a high proactive response capacity could prevent the introduction of the species but will still be at risk if other countries of first establishment in the region have a low proactive response capacity. In order to assess the prevalence of this issue we calculated the minimum and maximum proactive response capacity for every scenario to which an invasion conformed.

For each invasion, the pathways of introduction that could facilitate the introduction of the species to each country of first establishment were identified and we determined the impacts that the species could have in all the countries that could be invaded (see Appendix S1).

All analyses and plotting were performed in R (R Core Team, 2017) and ArcMap version 10.

\section{3 | RESULTS}

We predicted that introductions of the 86 invaders to regions with contiguous countries could result in 2,523 future biological invasions. Although many of the invaders could be introduced and become invasive in both developed and developing regions, the number of invaders that could have impacts is higher for developing regions than for developed regions (Figure S3). The pathways of introduction for most of the invaders are prominent in restricted parts of the studied regions, and so in many regions these species pose an introduction threat to a relatively confined area (Figure S3). However, large parts of these regions are environmentally suitable for these species and are sensitive to their impacts (Figure S3).

There were predicted invasions that conformed to all six of the invasion scenarios (Figure 1 and Table 1). Of the predicted future invasions, 1,550 could conform to scenarios 1 or 2 (Table 1), and so for most (61.4\%) of the predicted invasions the alien species will be introduced and establish in a country, but will not spread into neighbouring countries. These invasions will not pose a threat regionally, but in most cases are predicted to cause impacts, and so should be a national priority for management (Table 1 and Figure 1). Unfortunately, the majority of these invasions are unlikely to be prevented, due to the low proactive response capacity of the country in which they are predicted to occur (Table 1).

For more than a third of the predicted invasions (973 invasions or $38.6 \%$ ), the alien species is likely to be introduced and establish in a country and then subsequently spread into neighbouring countries (see results for scenarios 3-6 in Table 1 and for further details Figure S4). For 151 of these invasions, there is more than one country where the species could first establish and as a consequence multiple scenarios are possible (see Figure S4).

Of the invasions that are predicted to span multiple countries, 115 (4.6\%) could conform to scenario 3 and so are unlikely to cause impacts in any of the countries that the invasion spans (Table 1; Figure S4 for further details). Most of these invasions are likely to be prevented as the country where the species could first 
establish has a high proactive response capacity (Table 1 and for further details see Figure S5). In these instances, countries with high proactive response capacity could assist their neighbours by preventing invasions, but these invasions are not a management priority for the country of first establishment or for the region (Figure 1).
A few invasions (64 invasions; $2.5 \%$ ) could conform to scenario 5 and so will cause impacts in the country where the species first establishes, but will not cause impacts in any of the countries that are subsequently invaded (Table 1; Figure S4 for further details). These invasions should be a management priority for the country of first establishment, but not for the entire region (Figure 1). Most of

\begin{tabular}{|c|c|c|c|c|c|}
\hline \multicolumn{2}{|l|}{ Scenario } & \multirow{2}{*}{$\begin{array}{l}\text { Number of } \\
\text { invasions }\end{array}$} & \multicolumn{3}{|c|}{ Proactive response capacity } \\
\hline Number & Notation & & Low & Intermediate & High \\
\hline 1 & $\mathrm{FE}-\mathrm{X}->\mathrm{SI}$ & 326 & 145 & 47 & 63 \\
\hline 2 & $\mathrm{FE}^{*}-\mathrm{X}->\mathrm{SI}$ & 1,224 & 696 & 204 & 158 \\
\hline 3 & FE ---> SI & 115 & 29 & 16 & 69 \\
\hline 4 & $\mathrm{FE}^{*}--->\mathrm{SI}^{*}$ & 791 & 608 & 88 & 90 \\
\hline 5 & $\mathrm{FE}^{*}--->\mathrm{SI}$ & 64 & 20 & 18 & 18 \\
\hline 6 & FE --->SI* & 154 & 96 & 27 & 22 \\
\hline
\end{tabular}

Note: Information on proactive response capacity was not available for some invasions. Multiple scenarios are possible for 151 of the invasions that are predicted to spread into neighbouring countries (see Figure S4), and so the number of invasions conforming to the scenarios $(2,674)$ is greater than the total number of invasions predicted (2,523 invasions).

FE is the country of first establishment; $\mathrm{SI}$ is the country of subsequent invasion; ---> is spread; - $X->$ is no spread; *there are impacts; no asterisk there are no impacts. See Figure 1 for further details.
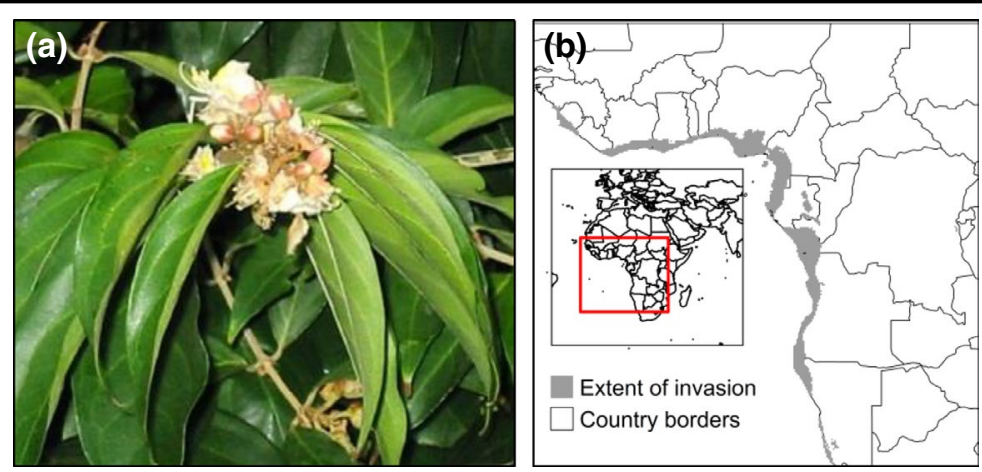

Native range and current invasions:

Hiptage is a vine-like shrub of the family Malpighiaceae that is native to south and SouthEast Asia (China, Taiwan, India, Indonesia, Malaysia, Myanmar, Philippines, Sri Lanka, and Thailand; Global Invasive Species Database, 2019; Starr, Starr, \& Loope, 2003). The species has been introduced to Australia, the USA (including Hawaii) and the islands of Mauritius and Réunion (Global Invasive Species Database, 2019; Starr et al., 2003), where it was cultivated as an ornamental plant and occasionally for medicinal purposes (Starr et al., 2003). Where the species has become invasive it climbs over and smothers native plants and prevents them from growing or regenerating (Pacific Island Ecosystems at Risk (PIER), 2013).

\section{Potential invasion:}

New introductions of this species are likely through the ornamental plant trade (CAB International, 2007), and the species could be introduced to the west coast of Africa, where it could establish and become invasive. Hiptage can be propagated from cuttings, and as the seeds of the plant are dispersed by the wind (Pacific Island Ecosystems at Risk (PIER), 2013), the species could easily spread in west Africa, resulting in an invasion that could span 15 countries. The species is likely to have environmental impacts in most of these countries, with the invasion overlapping with ecoregions that are priorities for conservation (Olson \& Dinerstein, 2002). As the countries in which impacts could occur include some of the 12 countries in the region where the species could first establish, the invasion could conform to either invasion scenario 4 or 6 . All of the countries in which the species could first establish have a low proactive response capacity. Consequently, this invasion is unlikely to be prevented, unless there is regional co-operation and communication.
TABLE 1 The number of invasions predicted to occur in regions with contiguous countries which conform to each scenario. For each invasion, the minimum proactive response capacity available in countries of first establishment (FE) was calculated, and expressed here is the number of invasions for which the minimum proactive response was low, intermediate or high. There will be low proactive response capacity to prevent most invasions
FIGURE 3 Hiptage (Hiptage benghalensis (L.) Kurz) (a) is predicted to invade the west coast of Africa (b), where the species could spread and have an impact 
these invasions are unlikely to be prevented due to the low proactive response capacity of the countries in which the species could first establish (Table 1 and for further details see Figure S5).

Almost a third of the predicted invasions (827 invasions, $32.8 \%$ ) could conform to scenario 4 and/or scenario 6 and, therefore, could have impacts in some of the countries that are subsequently invaded (see Figure S4). In these instances countries will rely on the biosecurity of their neighbours and so these invasions should be a management priority for the region. Unfortunately, the majority of these invasions are unlikely to be prevented due to the low proactive response capacity of some of the countries where the species could first establish (see Figure S6).

(a)

Likelihood of invasion

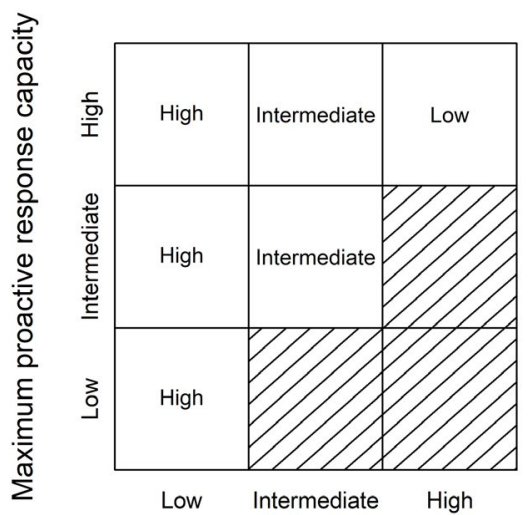

Minimum proactive response capacity
Almost a third of the invasions (791 invasions; 31.4\%) could conform to scenario 4 and so are likely to have impacts in both the country where the species first establishes and in some of the countries that are subsequently invaded (Table 1; Figure S4 for further details). One predicted invasion that could conform to this scenario is that of hiptage (Hiptage benghalensis (L.) Kurz) on the west coast of Africa (Figure 3). Such invasions should be a management priority for the country of first establishment, as well as for the entire region (Figure 1), but most of these invasions are unlikely to be prevented as some or all of the countries where the species could first establish have a low proactive response capacity (Table 1 and Figure 4). For some of these invasions, a subset of

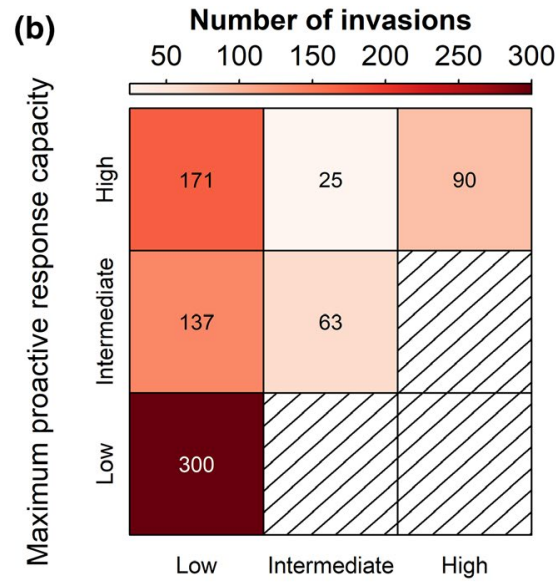

Minimum proactive response capacity

FIGURE 4 The minimum and maximum proactive response capacity of all of the potential countries of first establishment (FE) for invasions that conform to scenario 4 . In scenario 4 an invasive species has an impact in the country of first establishment, and spreads into countries of subsequent invasion (SI), where it also has an impact. Panel a shows the likelihood that an invasion will occur given the capacity available, and Panel b shows the number of invasions for which each section of the diagram is relevant. Information on proactive response capacity was not available for five invasions that conformed to this scenario

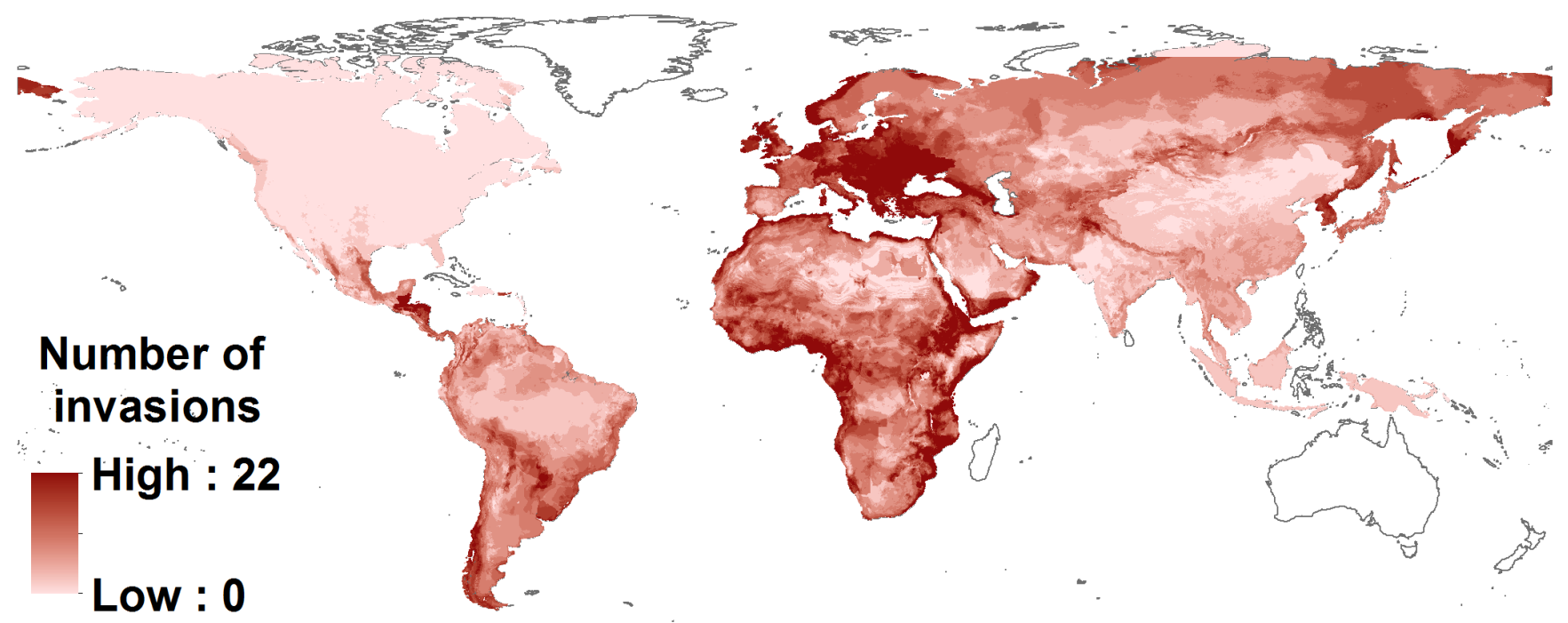

FIGURE 5 Regions with contiguous countries where invasions that conform to scenario 6 could occur. Invasions conform to scenario 6 when an invasive species spreads from the country of first establishment (FE), where there is no impact, into countries of subsequent invasion (SI), where there is an impact. Isolated countries (e.g. Australia) were not included in the analysis and are shown in white on the map 
the countries where first establishment could occur have a high proactive response capacity, however, these countries will still be at risk due to their neighbours' weak biosecurity (Figure 4).

Of the predicted invasions, 154 (6.1\%) could conform to scenario 6 and are unlikely to have impacts in the country where the species could first establish, but could have impacts in some of the countries that will be subsequently invaded (Table 1; Figure S4 for further details). Many of these invasions are predicted to occur in Africa, South and Central America, eastern Europe and the Middle East (Figure 5). Such invasions are unlikely to be a management priority for the country of first establishment, but should be a priority at a regional level (Figure 1). Therefore, these invasions are unlikely to be prevented, no matter the proactive response capacity available (but for details see Table 1; Figure S5), as there will be little incentive for the country of first establishment to prevent and manage the invasion. The predicted invasion of hiptage on the west coast of Africa could conform to this scenario and, therefore, is unlikely to be prevented (Figure 3).

\section{DISCUSSION}

Heterogeneous biosecurity can put regions with contiguous countries at risk of biological invasions, when one country acts as an entry point for harmful species that subsequently spread into neighbouring countries. While this issue is known to affect the biosecurity of regions with open borders, such as Europe (Bacon et al., 2012), our results show that this is a global issue that is likely to be a problem in all regions with contiguous countries. To prevent biological invasions and their impacts, the influence of heterogeneous biosecurity on regional invasion risks needs to be addressed, however, there are unlikely to be easy solutions.

Our analysis predicted that further introductions of wellknown invaders could result in thousands of future biological invasions in regions with contiguous countries, with most of these invasions likely to cause negative socio-economic or environmental impacts. The rate at which alien species are being introduced to new regions continues to increase (Seebens et al., 2017) and new invaders, which have no history of invasion, are still being introduced globally at a high rate (Seebens et al., 2018). These species and many other invaders that have a history of invasion were not included in this study as our stringent analysis was not possible for invaders that are not well-studied or for future invaders whose identity is unknown. However, we expect that many such invasions will also spread from the country of first establishment and cause significant negative impacts in neighbouring countries (i.e. scenarios 4 and 6 in Figure 1 will become increasingly common).

The well-known invaders included in our study are likely to be introduced and become invasive in many regions with contiguous countries, including developed and developing regions. While many of these invaders have already been introduced to developed regions, our results show that there are still opportunities available in these regions for some of these species to be introduced and become invasive. In line with our findings, a number of previous studies have predicted that the number of introductions and invasions in developing regions are set to increase dramatically (Early et al., 2016; Seebens et al., 2015; Turbelin et al., 2017; van Kleunen et al., 2015). This is not only as many well-known invaders have not yet been introduced to these regions, but also as there has been a recent increase in trade and transport between developing countries and other parts of the world (Early et al., 2016; Seebens et al., 2015; Turbelin et al., 2017; van Kleunen et al., 2015). Although many of these wellknown invaders could be introduced and become invasive in both developed and developing regions, the number that could have negative impacts appears to be greater in developing regions. This is not surprising as economies and food production in developing regions are particularly vulnerable, and as it is in these regions where most of the world's remaining biodiversity is found (Early et al., 2016). Most of the invaders are likely to be introduced to restricted parts of the studied regions, but large areas of these regions are environmentally suitable for these species and are sensitive to their impacts. Therefore, following introduction, these species are likely to become widespread and could have impacts far from where they were initially introduced. Consequently, the management actions required to prevent many of these harmful invasions will need to be implemented far from where there will be consequences.

Many alien species in regions with contiguous countries have not spread into neighbouring countries from the country where they were initially introduced (Chiron, Shirley, \& Kark, 2010; Faulkner et al., 2017; Lambdon et al., 2008; Roques et al., 2016). In line with these findings, most of the predicted invasions in our study are unlikely to spread from the country of first establishment into neighbouring countries. However, we did predict many invasions that could span multiple countries. If an alien species is introduced and establishes in a region with contiguous countries and large areas that are environmentally suitable, spread between these countries is highly likely. This is not only due to the high propagule pressure and short geographical distances that characterize these types of dispersal, but also because managing the natural dispersal of alien species is extremely difficult (Faulkner et al., 2017; Wilson, Dormontt, Prentis, Lowe, \& Richardson, 2009). As the movement of alien species between countries has recently increased in some regions, for example, continental Africa (Faulkner et al., 2017, 2020), the prominence of invasions that span multiple countries could be increasing (Stoett, 2007).

While a number of factors could limit the extent of invasions (e.g. the environment, limited dispersal capabilities), our analysis only considered whether a species is likely to be introduced and find a suitable environment in a new region, and so we assumed that the species could disperse to all areas that are suitable. Species vary in their dispersal capabilities and so for some of the predicted invasions the extent of the invasion and its impacts may be overestimated. However, it is important to note that all the species considered in this analysis have previously demonstrated their ability to invade 
and are unlikely to be limited by poor dispersal capabilities. In the development of the stringent analysis used in this study many other necessary assumptions were made and a number of thresholds were applied to generate the introduction threat, invasion threat and impact results. For example, we assumed that the pathways that have facilitated the introduction of the studied species in the past will continue to do so in the future, and that species are most likely to be introduced where their pathways of introduction are most prominent. However, pathways of introduction vary over time (Essl et al., 2015), and so in the future these species could be introduced through pathways that have not previously facilitated their introduction. Furthermore, while the likelihood of introduction is often positively related to the prominence of a species' pathways of introduction, this is not always the case and other factors (e.g. the size of the species pool and biosecurity) could influence the strength of this link (Sikes et al., 2018). Our assumptions and simplifications undoubtedly influenced the outputs, and as a consequence the number of invasions, their extent and impacts could be overestimated. However, we believe that it is more likely that the invasions and their impacts are underestimated as many more species than the 86 included in this study will become invasive in the future (see above) and as in most cases our estimates and thresholds erred on the conservative side. While these assumptions will influence how many of the invasions conform to the different scenarios, it is clear that the overall conclusion holds-biosecurity is often a regional issue. Regional biosecurity needs both regional pathway-specific management, and species-specific plans that consider prevention, contingency planning, containment and impact reduction. Such regional planning must be underpinned by detailed context-specific distribution and spread models (ideally based on mechanistic understanding of the underlying processes). The models presented here are not intended for such a purpose.

The capacity to manage invasions varies across countries (Early et al., 2016), and although the assumption has been made that developed countries have a high capacity and developing countries have a low capacity (Ricciardi et al., 2017), this has been refuted (Zenni, Ziller, Pauchard, Rodriguez-Cabal, \& Nuñez, 2017). In general, the capacity to manage invasions is low all over the world (Zenni et al., 2017), particularly the capacity to prevent invasions (Early et al., 2016; Turbelin et al., 2017), with exceptions being countries where there are many invasive species and where invasions have been particularly devastating (Turbelin et al., 2017; Zenni et al., 2017). As a consequence, most of the invasions predicted in this study, whether they span multiple countries or not, are unlikely to be prevented. This is especially worrying as the studied species have had serious impacts where introduced and are listed as some of the world's worst invasive species, and as the thousands of biological invasions predicted here are only a small proportion of those that could occur in the future.

The majority of the invasions that were predicted to span one country are likely to cause impacts, and so should be a national management priority. However, as these invasions will not spread into neighbouring countries, there will be no undesirable consequences for neighbouring countries if the country where the invasion is predicted has weak biosecurity. In contrast, when invasions span multiple countries, some of the countries involved will have to rely on the biosecurity of a neighbouring country. Although countries with good biosecurity could assist their neighbours by preventing invasions, as we show here, this scenario tends to occur in regions where there are unlikely to be impacts. For almost a third of the predicted invasions, countries where impacts could occur will have to rely on a neighbouring country's biosecurity, and in most cases these countries have a low proactive response capacity. For most of the predicted invasions that could cause impacts in countries that are subsequently invaded, countries will rely on the biosecurity of a neighbour where the invasion will cause impacts. In these instances, countries with weak biosecurity will put themselves and their neighbours at risk (independent of the capacity of neighbouring countries to prevent invasions). The countries affected by these invasions will, however, have a shared interest in preventing the invasion. Unfortunately, this is not always the case, and in some instances countries will rely on the biosecurity of a neighbouring country in which the invasion will not cause an impact. Management priorities are usually determined at a national level (e.g. Branquart, 2007; Faulkner, Robertson, Rouget, \& Wilson, 2014; Locke, 2009), and countries are unlikely to direct limited resources to prevent invasions that are not national priorities. These invasions are, therefore, particularly concerning as they are unlikely to be prevented, even in instances where all of the countries involved have good biosecurity. In regions with open borders, such situations could be exploited. In these regions imports are only checked at the first point of entry, and so species could be imported into a country where it is legal to do so, and then moved into countries within the same region where import is illegal. Additionally, efforts to prevent these invasions could cause conflicts of interest if the country of first establishment stands to derive benefits from the introduction of the alien species. For example, sweet prickly pear (Opuntia ficus-indica (L.) Mill.) is an agricultural crop in Mediterranean countries, and in order to control the false carmine cochineal scale (Dactylopius opuntiae Cockerell), a serious pest of prickly pear in this region, biological control agents [e.g. mealybug destroyer (Cryptolaemus montrouzieri Mulsant)] have been released (Mazzeo, Nucifora, Russo, \& Suma, 2019). As biological control agents can unintentionally spread between countries (Pratt \& Center, 2012), the release of these agents in countries like Morocco could negatively impact cactus biocontrol in South Africa and Kenya, where sweet prickly pear is highly invasive and the false carmine cochineal scale is used as a biological control agent (Winston et al., 2014). Therefore, while countries with a low capacity to prevent invasions put their neighbours at risk, so too do those with biosecurity protocols that only focus on national risks. This issue likely poses a challenge for management in all regions with contiguous countries. However, the consequences of failing to prevent these invasions are likely to be greater in developing regions, where the management of invasions that span multiple countries is also most likely to cause conflicts of interest. 
In conclusion, our study predicted that further introductions of well-known invaders could result in thousands of biological invasions, with most predicted to have negative environmental or socio-economic impacts. Most of the predicted invasions are unlikely to be prevented. Our results, therefore, further support the view that better international policies need to be developed (Ricciardi et al., 2017; Sikes et al., 2018) and that improvements to national-level biosecurity are required (Zenni et al., 2017). However, for almost a third of the predicted invasions, countries where impacts could occur will rely on the biosecurity of a neighbouring country. To prevent these invasions strong, regional biosecurity is vital. Actions to achieve this will have global benefits as species are often introduced to new regions from their introduced range (Bertelsmeier et al., 2018), and so improvements to national and regional biosecurity will also reduce the threats posed to other regions. The challenge of developing regional biosecurity is partly addressed by regional plant pest organizations (e.g. The North American Plant Protection Organization and European and Mediterranean Plant Protection Organization), and supranational regulations clearly have a part to play (e.g. EU Regulation 1143/2014; EU, 2014). Frameworks have also been developed to assist with such co-ordinated regional responses (Faulkner et al., 2017; Genovesi, Scalera, Brunel, \& Roy, 2010). Despite this, most strategies to prevent invasions are implemented at a national level (Stoett, 2007). The scientific community and policymakers have also given little attention to the transboundary nature of biological invasions, and the proposed indicators to measure progress towards achieving global targets that aim to minimize the impacts of biological invasions (The Convention on Biological Diversity's Aichi Biodiversity Target 9 [https://www.cbd.int/sp/targets/]) are often at a national level (Latombe et al., 2017; Wilson et al., 2018; but see Rabitsch et al., 2016). As such there is no explicit incentive to prevent invasions that are not a national priority. Therefore, we propose that explicit support for regional biosecurity initiatives be included in future targets, as this will help to address the problem identified in this paper, and could reduce the likelihood of conflicts of interest in regions where the impacts of biological invasions are likely to be most severe.

\section{ACKNOWLEDGEMENTS}

We thank Regan Early and Bethany Bradley for kindly providing data on proactive response capacity. We also thank Tanya Strydom for her help with extracting data, Mathieu Rouget for his input in initial discussions of this work and Piero Genovesi for his useful comments on a draft of this manuscript. The South African Department of Environment, Forestry, and Fisheries (DEFF) are thanked for funding, noting that this publication does not necessarily represent the views or opinions of DEFF or its employees.

\section{DATA AVAILABILITY STATEMENT}

The data that support the findings of this study are available in the supplementary material of this article or are available from the corresponding author upon reasonable request. These data were derived from resources available in the public domain, details of which are provided in the supplementary materials.

\section{ORCID}

Katelyn T. Faulkner (DD https://orcid.org/0000-0002-3955-353X

Mark P. Robertson (iD https://orcid.org/0000-0003-3225-6302

John R. U. Wilson (iD https://orcid.org/0000-0003-0174-3239

\section{REFERENCES}

Allouche, O., Tsoar, A., \& Kadmon, R. (2006). Assessing the accuracy of species distribution models: Prevalence, kappa and the true skill statistic (TSS). Journal of Applied Ecology, 43, 1223-1232. https://doi. org/10.1111/j.1365-2664.2006.01214.x

Bacon, S. J., Bacher, S., \& Aebi, A. (2012). Gaps in border controls are related to quarantine alien insect invasions in Europe. PLoS ONE, 7(10), e47689. https://doi.org/10.1371/journal.pone.0047689

Bellard, C., Cassey, P., \& Blackburn, T. M. (2016). Alien species as a driver of recent extinctions. Biology Letters, 12, 20150623. https://doi. org/10.1098/rsbl.2015.0623

Benedict, M. Q., Levine, R. S., Hawley, W. A., \& Lounibos, L. P. (2007). Spread of the tiger: Global risk of invasion by the mosquito Aedes albopictus. Vector-Borne and Zoonotic Diseases, 7(1), 76-85.

Bertelsmeier, C., Ollier, S., Liebhold, A. M., Brockerhoff, E. G., Ward, D., \& Keller, L. (2018). Recurrent bridgehead effects accelerate global alien ant spread. Proceedings of the National Academy of Sciences of the United States of America, 115, 5486-5491. https://doi.org/10.1073/ pnas.1801990115

Blackburn, T. M., Pyšek, P., Bacher, S., Carlton, J. T., Duncan, R. P., Jarošík, V., ... Richardson, D. M. (2011). A proposed unified framework for biological invasions. Trends in Ecology \& Evolution, 26(7), 333-339. https://doi.org/10.1016/j.tree.2011.03.023

Branquart, E. (2007). Guidelines for environmental impact assessment and list classification of non-native organisms in Belgium. Belgium: Belgium Forum on Invasive Species.

Brenton-Rule, E. C., Barbieri, R. F., \& Lester, P. J. (2016). Corruption, development and governance indicators predict invasive species risk from trade. Proceedings of the Royal Society B, 283, 20160901. https ://doi.org/10.1098/rspb.2016.0901

CAB International. (2007). Hiptage benghalensis (hiptage). Retrieved from https://www.cabi.org/ISC/datasheet/27228\#654A77C2-2CA1461E-AE38-D108922DA32D

CBD. (2014). Pathways of introduction of invasive species, their prioritization and management. Retrieved from https://www.cbd.int/doc/ meetings/sbstta/sbstta-18/official/sbstta-18-09-add1-en.pdf

Chiron, F., Shirley, S. M., \& Kark, S. (2010). Behind the Iron Curtain: Socio-economic and political factors shaped exotic bird introductions into Europe. Biological Conservation, 143, 351-356. https://doi. org/10.1016/j.biocon.2009.10.021

Drake, J.M., \&Lodge, D. M. (2004). Global hotspots of biologicalinvasions: Evaluating options for ballast - Water management. Proceedings of the Royal Society of London B, 271(1539), 575-580. https://doi.org/ 10.1098/rspb.2003.2629

Early, R., Bradley, B. A., Dukes, J. S., Lawler, J. J., Olden, J. D., Blumenthal, D. M., ... Tatem, A. J. (2016). Global threats from invasive alien species in the twenty-first century and national response capacities. Nature Communications, 7, 12485. https://doi.org/10.1038/ncomms12485

Eschen, R., Britton, K., Brockerhoff, E., Burgess, T., Dalley, V., EpanchinNiell, R. S., ... Theyse, M. (2015). International variation in phytosanitary legislation and regulations governing importation of plants for planting. Environmental Science \& Policy, 51, 228-237. https://doi. org/10.1016/j.envsci.2015.04.021

Essl, F., Bacher, S., Blackburn, T. M., Booy, O., Brundu, G., Brunel, S., ... Jeschke, J. M. (2015). Crossing frontiers in tackling pathways 
of biological invasions. BioScience, 65, 769-782. https://doi.org/ 10.1093/biosci/biv082

EU. (2014). Regulation (EU) No 1143/2014 of the European Parliament and of the Council of 22 October 2014 on the prevention and management of the introduction and spread of invasive alien species. Official Journal of the European Union, 57, 35-55.

Faulkner, K. T., Burness, A., Byrne, M., Kumschick, S., Peters, K., Robertson, M. P., ... Weyl, O. L. F. (2020). South Africa's pathways of introduction and dispersal and how they have changed over time. In B. W. van Wilgen, J. Measey, D. M. Richardson, J. R. Wilson, \& T. A. Zengeya (Eds.), Biological invasions in South Africa (pp. 311-352). Cham, Switzerland: Springer. https://doi.org/10.1007/978-3-030-32394-3_12

Faulkner, K. T., Hurley, B. P., Robertson, M. P., Rouget, M., \& Wilson, J. R. U. (2017). The balance of trade in alien species between South Africa and the rest of Africa. Bothalia: African Biodiversity and Conservation, 47(2), a2157.

Faulkner, K. T., Robertson, M. P., Rouget, M., \& Wilson, J. R. U. (2014) A simple, rapid methodology for developing invasive species watch lists. Biological Conservation, 179, 25-32. https://doi.org/10.1016/j. biocon.2014.08.014

Fielding, A. H., \& Bell, J. F. (1997). A review of methods for the assessment of prediction errors in conservation presence/absence models. Environmental Conservation, 24(1), 38-49. https://doi.org/10.1017/ S0376892997000088

Foxcroft, L. C., Spear, D., van Wilgen, N. J., \& McGeoch, M. A. (2019). Assessing the association between pathways of alien plant invaders and their impacts in protected areas. NeoBiota, 43, 1-25. https://doi. org/10.3897/neobiota.43.29644

Genovesi, P., Scalera, R., Brunel, S., \& Roy, D. (2010). Towards an early warning and information system for invasive alien species (IAS) threatening biodiversity in Europe. In European Environment Agency Technical report. Retrieved from http://scholar.google.com/ scholar?hl=en\&btnG=Search\&q=intitle:Towards+an+early+warni ng+and+information+system+for+invasive+alien+species+(IAS)+threatening+biodiversity+in+Europe\#0

Global Invasive Species Database. (2019). Species profile: Hiptage benghalensis. Retrieved from http://www.iucngisd.org/gisd/speciesnam e/Hiptage+benghalensis

Haack, R. A. (2001). Intercepted Scolytidae (Coleoptera) at U.S. ports of entry: 1985-2000. Integrated Pest Management Reviews, 6, 253-282.

Halpern, B. S., Frazier, M., Potapenko, J., Casey, K. S., Koenig, K., Longo, C., ... Walbridge, S. (2015). Cumulative human impacts: Raw stressor data (2008 and 2013). Retrieved from https://knb.ecoinformatics. org/view/doi:10.5063/F1S180FS

Harrari, Y. N. (2015). Sapiens: A brief history of mankind. London, UK: Penguin Random House.

Hijmans, R. J., Cameron, S. E., Parra, J. L., Jones, P. G., \& Jarvis, A. (2005). Very high resolution interpolated climate surfaces for global land areas. International Journal of Climatology, 25, 1965-1978. https:// doi.org/10.1002/joc.1276

Hulme, P. E. (2009). Trade, transport and trouble: Managing invasive species pathways in an era of globalization. Journal of Applied Ecology, 46, 10-18. https://doi.org/10.1111/j.1365-2664.2008.01600.x

Kaluza, P., Kölzsch, A., Gastner, M. T., \& Blasius, B. (2010). The complex network of global cargo ship movements. Journal of the Royal Society, Interface, 7, 1093-1103. https://doi.org/10.1098/rsif.2009.0495

Lambdon, P. W., Pyšek, P., Basnou, C., Hejda, M., Arianoutsou, M., Essl, F., ... Hulme, P. E. (2008). Alien flora of Europe: Species diversity, temporal trends, geographical patterns and research needs. Preslia, 80, 101-149.

Latombe, G., Pyšek, P., Jeschke, J. M., Blackburn, T. M., Bacher, S., Capinha, C., ... McGeoch, M. A. (2017). A vision for global monitoring of biological invasions. Biological Conservation, 213, 295-308. https:// doi.org/10.1016/j.biocon.2016.06.013

Leung, B., Lodge, D. M., Finnoff, D., Shogren, J. F., Lewis, M. A., \& Lamberti, $\mathrm{G}$. (2002). An ounce of prevention or a pound of cure: Bioeconomic risk analysis of invasive species. Proceedings of the Royal Society of London B, 269, 2407-2413. https://doi.org/10.1098/rspb.2002.2179

Levine, J. M., \& D'Antonio, C. M. (2003). Forecasting biological invasions with increasing international trade. Conservation Biology, 17(1), 322326. https://doi.org/10.1046/j.1523-1739.2003.02038.x

Locke, A. (2009). A screening procedure for potential tunicate invaders of Atlantic Canada. Aquatic Invasions, 4(1), 71-79. https://doi. org/10.3391/ai.2009.4.1.7

Lowe, S., Browne, M., Boudjelas, S., \& De Poorter, M. (2000). 100 of the world's worst invasive alien species: A selection from the Global Invasive Species Database. Auckland, New Zealand: The Invasive Species Specialist Group.

Luque, G. M., Bellard, C., Bertelsmeier, C., Bonnaud, E., Genovesi, P., Simberloff, D., \& Courchamp, F. (2014). The 100th of the world's worst invasive alien species. Biological Invasions, 16(5), 981-985. https://doi.org/10.1007/s10530-013-0561-5

Mazzeo, G., Nucifora, S., Russo, A., \& Suma, P. (2019). Dactylopius opuntiae, a new prickly pear cactus pest in the Mediterranean: An overview. Entomologia Experimentalis et Applicata, 167, 59-72.

McGeoch, M. A., Butchart, S. H. M., Spear, D., Marais, E., Kleynhans, E. J., Symes, A., ... Hoffmann, M. (2010). Global indicators of biological invasion: Species numbers, biodiversity impact and policy responses. Diversity and Distributions, 16, 95-108. https://doi. org/10.1111/j.1472-4642.2009.00633.x

McGeoch, M. A., Genovesi, P., Bellingham, P. J., Costello, M. J., McGrannachan, C., \& Sheppard, A. (2016). Prioritizing species, pathways, and sites to achieve conservation targets for biological invasion. Biological Invasions, 18(2), 299-314. https://doi.org/10.1007/ s10530-015-1013-1

Olson, D. M., \& Dinerstein, E. (2002). The global 200: Priority ecoregions for global conservation. Annals of the Missouri Botanical Garden, 89(2), 199-224. https://doi.org/10.2307/3298564

Pacific Island Ecosystems at Risk (PIER). (2013). Invasive plant species: Hiptage benghalensis (L.) Kurz, Malpighiaceae. Retrieved from http:// www.hear.org/pier/species/hiptage_benghalensis.htm

Pagad, S., Genovesi, P., Carnevali, L., Schigel, D., \& McGeoch, M. A. (2018). Data descriptor: Introducing the global register of introduced and invasive species. Scientific Data, 5, 170102. https://doi. org/10.1038/sdata.2017.202

Pergl, J., Pyšek, P., Bacher, S., Essl, F., Genovesi, P., Harrower, C. A., ... Nentwig, W. (2017). Troubling travellers: Are ecologically harmful alien species associated with particular introduction pathways? NeoBiota, 32, 1-20. https://doi.org/10.3897/neobiota.32.10199

Pimentel, D., McNair, S., Janecka, J., Wightman, J., Simmonds, C., O'Connell, C., ... Tsomondo, T. (2001). Economic and environmental threats of alien plant, animal, and microbe invasions. Agriculture, Ecosystems and Environment, 84, 1-20. https://doi.org/10.1016/ S0167-8809(00)00178-X

Pimentel, D., Zuniga, R., \& Morrison, D. (2005). Update on the environmental and economic costs associated with alien-invasive species in the United States. Ecological Economics, 52(3), 273-288. https://doi. org/10.1016/j.ecolecon.2004.10.002

Pratt, P. D., \& Center, T. D. (2012). Biocontrol without borders: The unintended spread of introduced weed biological control agents. BioControl, 57, 319-329. https://doi.org/10.1007/s10526-011-9412-4

Puth, L. M., \& Post, D. M. (2005). Studying invasion: Have we missed the boat? Ecology Letters, 8, 715-721. https://doi.org/10.1111/j.14610248.2005.00774.x

R Core Team. (2017). R: A language and environment for statistical computing. Vienna, Austria: R Foundation for Statistical Computing. Retrieved from http://www.r-project.org/

Rabitsch, W., Genovesi, P., Scalera, R., Biała, K., Josefsson, M., \& Essl, F. (2016). Developing and testing alien species indicators for Europe. Journal for Nature Conservation, 29, 89-96. https://doi.org/10.1016/j. jnc.2015.12.001 
Ricciardi, A., Blackburn, T. M., Carlton, J. T., Dick, J. T. A., Hulme, P. E., lacarella, J. C., ... Aldridge, D. C. (2017). Invasion science: A horizon scan of emerging challenges and opportunities. Trends in Ecology \& Evolution, 32(6), 464-474. https://doi.org/10.1016/j.tree.2017.03.007

Robertson, M. P., Visser, V., \& Hui, C. (2016). Biogeo: An R package for assessing and improving data quality of occurrence record datasets. Ecography, 39(4), 394-401. https://doi.org/10.1111/ecog.02118

Roques, A., Auger-Rozenberg, M.-A., Blackburn, T. M., Garnas, J., Pyšek, P., Rabitsch, W., ... Duncan, R. P. (2016). Temporal and interspecific variation in rates of spread for insect species invading Europe during the last 200 years. Biological Invasions, 18(4), 907-920.

Sala, O. E., Chapin, F. S., Armesto, J. J., Berlow, E., Bloomfield, J., Dirzo, R., ... Wall, D. H. (2000). Global biodiversity scenarios for the year 2100. Science, 287, 1770-1774.

Seebens, H., Blackburn, T. M., Dyer, E. E., Genovesi, P., Hulme, P. E., Jeschke, J. M., ... Essl, F. (2017). No saturation in the accumulation of alien species worldwide. Nature Communications, 8, 14435. https:// doi.org/10.1038/ncomms14435

Seebens, H., Blackburn, T. M., Dyer, E. E., Genovesi, P., Hulme, P. E., Jeschke, J. M., ... Essl, F. (2018). Global rise in emerging alien species results from increased accessibility of new source pools. Proceedings of the National Academy of Sciences of the United States of America, 115(10), E2264-E2273. https://doi.org/10.1073/pnas.1719429115

Seebens, H., Essl, F., Dawson, W., Fuentes, N., Moser, D., Pergl, J., ... Blasius, B. (2015). Global trade will accelerate plant invasions in emerging economies under climate change. Global Change Biology, 21(11), 4128-4140. https://doi.org/10.1111/gcb.13021

Seebens, H., Gastner, M. T., \& Blasius, B. (2013). The risk of marine bioinvasion caused by global shipping. Ecology Letters, 16(6), 782-790. https://doi.org/10.1111/ele.12111

Sikes, B. A., Bufford, J. L., Hulme, P. E., Cooper, J. A., Johnston, P. R., \& Duncan, R. P. (2018). Import volumes and biosecurity interventions shape the arrival rate of fungal pathogens. PLoS Biology, 16(5), e2006025. https://doi.org/10.1371/journal.pbio.2006025

Simberloff, D., Martin, J.-L., Genovesi, P., Maris, V., Wardle, D. A., Aronson, J., ... Vilà, M. (2013). Impacts of biological invasions: What's what and the way forward. Trends in Ecology \& Evolution, 28(1), 5866. https://doi.org/10.1016/j.tree.2012.07.013

Starr, F., Starr, K., \& Loope, L. (2003). Plants of Hawaii report - Hiptage benghalensis. In Weed Biology and Management. Retrieved from http:// www.hear.org/PIER/pdf/pohreports/hiptage_benghalensis.pdf

Stoett, P. J. (2007). Counter-bioinvasion: Conceptual and governance challenges. Environmental Politics, 16(3), 433-452. https://doi.org/ 10.1080/09644010701251672

Thuiller, W., Lafourcade, B., Engler, R., \& Araújo, M. B. (2009). BIOMOD - A platform for ensemble forecasting of species distributions. Ecography, 32, 369-373. https://doi.org/10.1111/j.1600-0587.2008.05742.x

Thuiller, W., Richardson, D. M., Pyšek, P., Midgley, G. F., Hughes, G. O., $\&$ Rouget, M. (2005). Niche-based modelling as a tool for predicting the risk of alien plant invasions at a global scale. Global Change Biology, 11, 2234-2250. https://doi.org/10.1111/j.1365-2486.2005.001 018.x

Title, P. O., \& Bemmels, J. B. (2018). ENVIREM: An expanded set of bioclimatic and topographic variables increases flexibility and improves performance of ecological niche modeling. Ecography, 41, 291-307. https://doi.org/10.1111/ecog.02880

Turbelin, A. J., Malamud, B. D., \& Francis, R. A. (2017). Mapping the global state of invasive alien species: Patterns of invasion and policy responses. Global Ecology and Biogeography, 26, 78-92. https://doi. org/10.1111/geb.12517

Tyberghein, L., Verbruggen, H., Pauly, K., Troupin, C., Mineur, F., \& De Clerck, O. (2012). Bio-ORACLE: Aglobal environmental datasetformarine species distribution modelling. Global Ecology and Biogeography, 21(2), 272-281. https://doi.org/10.1111/j.1466-8238.2011.00656.x van Kleunen, M., Dawson, W., Essl, F., Pergl, J., Winter, M., Weber, E., ... Pyšek, P. (2015). Global exchange and accumulation of non-native plants. Nature, 525, 100-103. https://doi.org/10.1038/nature14910

Wilson, J. R. U., Dormontt, E. E., Prentis, P. J., Lowe, A. J., \& Richardson, D. M. (2009). Something in the way you move: Dispersal pathways affect invasion success. Trends in Ecology \& Evolution, 24(3), 136-144. https://doi.org/10.1016/j.tree.2008.10.007

Wilson, J. R. U., Faulkner, K. T., Rahlao, S. J., Richardson, D. M., Zengeya, T. A., \& van Wilgen, B. W. (2018). Indicators for monitoring biological invasions at a national level. Journal of Applied Ecology, 55(6), 26122620. https://doi.org/10.1111/1365-2664.13251

Wilson, J. R. U., Panetta, F. D., \& Lindgren, C. (2017). Detecting and responding to alien plant incursions. Cambridge, UK: Cambridge University Press.

Winston, R. L., Schwarzländer, M., Hinz, H. L., Day, M. D., Cock, M. J. W., \& Julien, M. H. (2014). Biological control of weeds: A world catalogue of agents and their target weeds (5th ed.). Morgantown, West Virginia: USDA Forest Service, Forest Health Technology Enterprise Team.

Wisz, M. S., Hijmans, R. J., Li, J., Peterson, A. T., Graham, C. H., \& Guisan, A., \& NCEAS Predicting Species Distributions Working Group. (2008). Effects of sample size on the performance of species distribution models. Diversity and Distributions, 14, 763-773. https://doi. org/10.1111/j.1472-4642.2008.00482.x

World Travel and Tourism Council. (2016). Data gateway. Retrieved from https://www.wttc.org/datagateway/

World Wildlife Fund (2012). Global 200. Retrieved from https://www. worldwildlife.org/publications/global-200

Zenni, R. D., Ziller, S. R., Pauchard, A., Rodriguez-Cabal, M., \& Nuñez, M. A. (2017). Invasion science in the developing world: A response to Ricciardi et al Trends in Ecology \& Evolution, 32(11), 807-808. https:// doi.org/10.1016/j.tree.2017.08.006

\section{SUPPORTING INFORMATION}

Additional supporting information may be found online in the Supporting Information section.

How to cite this article: Faulkner KT, Robertson MP, Wilson JRU. Stronger regional biosecurity is essential to prevent hundreds of harmful biological invasions. Glob Change Biol. 2020;00:1-14. https://doi.org/10.1111/gcb.15006 